\title{
Physical activity and nutrition intervention for mothers of young children: Process evaluation
}

\author{
Sarojini M. D. R. Monteiro ${ }^{1}$, Jonine Jancey ${ }^{1 *}$, Peter Howat ${ }^{1,2}$ \\ ${ }^{1}$ Western Australian Centre for Health Promotion Research, School of Public Health, Curtin University, Perth, Australia; \\ *Corresponding Author: J>Jancey@curtin.edu.au \\ ${ }^{2}$ Centre for Behavioural Research in Cancer Control, School of Public Health, Curtin University, Perth, Australia
}

Received 27 November 2013; revised 2 January 2014; accepted 11 January 2014

Copyright (C) 2014 Sarojini M. D. R. Monteiro et al. This is an open access article distributed under the Creative Commons Attribution License, which permits unrestricted use, distribution, and reproduction in any medium, provided the original work is properly cited. In accordance of the Creative Commons Attribution License all Copyrights (c) 2014 are reserved for SCIRP and the owner of the intellectual property Sarojini M. D. R. Monteiro et al. All Copyright @ 2014 are guarded by law and by SCIRP as a guardian.

\section{ABSTRACT}

Introduction: Process evaluation of community based projects is integral to understanding the success or failure of health promotion interventions. Process evaluation was used to assess the intervention strategies and resources in a playgroup setting aimed at mothers of young children. Methods: Process evaluation data were collected from participants $(n=249)$ and staff $(n$ $=25$ ) involved in the intervention. Data included staff perspectives on use of the playgroup as a setting, participants' views on the feasibility and acceptability of the program strategies and resources, and program reach. Results: Responding participants reported that the intervention was useful (98\%) and relevant for their age group (92\%), encouraged them to think about making changes to their physical activity (95\%) and dietary (98\%) behaviors, and helped them to make changes to their physical activity (66\%) and dietary $(79 \%)$ behaviors. Participants reported that the most useful intervention strategies included the program booklet (85\%), workshops (86\%), newsletters (73\%) and SMS (57\%). Conclusion: This research provides valuable information on participants' perspectives of the program strategies, content and overall implementation. It provides insight into the feasibility and acceptability of the intervention and identifies areas for improvement when conducting programs in playgroup settings. The process evaluation indicated that playgroups are a suitable setting for health promotion targeting mothers of young children.

\section{KEYWORDS}

Diet; Physical Activity; Process Evaluation

\section{INTRODUCTION}

Physical inactivity, overweight and obesity, high blood pressure and high blood sugar are among the five leading global risks for mortality in the world [1]. According to the World Health Organisation (WHO), decreased physical activity, fruit and vegetable consumption and increased sugar and fat consumption are identified as major risk factors for cardiovascular diseases, cancer, metabolic syndrome and obesity [2].

Women are at increased risk of weight gain during their childbearing years and across the life span [3]. Obesity during pregnancy, the perinatal and the postpartum period has several negative consequences for the obese woman. Some of these include gestational diabetes mellitus, pre-eclampsia, thromboembolic disease, postpartum haemorrhage, spontaneous onset of labour and increased risk of anaesthetic complications [4]. Maternal obesity is associated with several major risks to the fetus, such as congenital abnormalities, macrosomia and increased risk of intrauterine death [5].

The Australian Dietary Guidelines recommend that women (19 to 60 years) eat at least four to seven serves of vegetables and legumes and three serves of fruit daily. However, 96\% of females aged 25 - 34 years and 94\% aged 35 - 44 years fail to meet these guidelines [6]. While women's physical activity levels decrease significantly after childbirth, due to life transitions that affect their priorities and lifestyle, it often results in insufficient daily levels of physical activity [7].

Research interventions have had varying degrees of 
success in increasing fruit and vegetable consumption and levels of physical activity among mothers with young children $[8,9]$. However, the recruitment and retention of participants into community based interventions are challenging due to the increased demands on these women, which include limited time and competing priorities [10].

Process evaluation is identified as an important reporting aspect of the CONSORT statement for public health research interventions [11,12] and is regarded as an essential component of health promotion program evaluation [13]. Process evaluation measures variation in program activities, reach, participant satisfaction and perception, and quality and delivery of the program strategies and takes into account or limits the influence of Type III errors in health promotion practice $[14,15]$.

Program evaluation in health promotion is a complex process as it aims to gather evidence to assess the effectiveness of strategies and programs, maintain a level of accountability [16] and improve health promotion practice [17]. Despite impact and outcome evaluation being the most commonly reported forms of evaluation for randomised controlled trials, process evaluation, which is under reported, is vital as it accounts for factors that contribute to the success or failure of programs $[18,19]$.

The intervention (program) aimed to encourage participants to increase their levels of physical activity and strength exercises and to improve their diet by increasing fruit, vegetable and fibre intake and decreasing their fat and added sugar intake. Information about the program protocol has been previously published [20]. This paper reports the main process evaluation conducted with program staff and the mothers of young children participating in the playgroup based program.

\section{METHOD}

\subsection{Theoretical Framework}

The program's strategies were based on a robust process [21] using the PRECEDE-PROCEED Model [22] as the overall conceptual framework and the Social Cognitive Theory constructs such as [23], self-efficacy and goal setting, along with motivational interviewing [24]. These constructs helped to inform the intervention strategies and design. Materials and strategies designed for the intervention had a strong emphasis on improving participants' self-efficacy relating to both dietary intake and physical activity behaviour. Information presented at workshops and written resources highlighted barriers and motivators (intrinsic and extrinsic) for achieving adequate levels of physical activity and a healthy diet. The workshop sessions helped equip participants with skills and knowledge to better manage their physical activity and dietary behaviours. For example, information on how to read food labels and tips on healthy dietary choices were provided, while text messaging reinforced healthy food choices. The program also supported goal setting, related to dietary and physical activity behaviour change and assessment of these goals as the intervention progressed.

\subsection{Intervention}

The six month intervention used four primary approaches to reach the population of interest (mothers of young children based in playgroups-playgroups are nonprofit organisations, that are locally based, providing a place for children aged 0 - 4 years and their mothers' to meet, play and socialise): 1) A comprehensive program booklet was produced based on the Australian Dietary Guidelines [25] and Physical Activity Guidelines [26]. This contained information about sample menus, understanding food labels, healthy eating tips and how to increase physical activity, along with behaviour change and goal setting information. 2) Six 30 minute workshops were delivered by trained program staff (one per month) in the playgroup setting. Detailed information about staff training and workshop content has been previously published [20]. 3) Six Newsletters containing chatty health information were posted or emailed over the six month intervention period. Eighteen Short Message Service (SMS) about nutrition and physical activity were sent to participants along with 12 messages reminding them to attend the face-to-face workshops. 4) Additional HomeBased Resources were provided to all participants to support behaviour change at home and to assist participants when they were unable to attend the workshops. These resources included: a pedometer to record their number of steps on a daily basis; a menu planner chart containing information about the Australian dietary and physical activity guidelines [25-27] for the entire family; a shopping list with tips designed to help participants to understand food labels, containing information about sugar, fat and fibre in packaged foods; a strength and flexibility exercise chart; a physical activity diary; and a recipe booklet.

\subsection{Intervention Program Staff}

The trained program staff $(n=25)$ were an integral component of the six month intervention. They were recruited via universities and health associations. They were required to have good interpersonal communication skills, an ability to work with minimal supervision in a team environment and previous experience conducting group education sessions or workshops. They were provided with intensive training about the application of the 
physical activity guidelines [26,27], nutrition guidelines [25], motivational interviewing [24], and Social Cognitive Theory [23]. The program staff members were responsible for implementing the program in the playgroups, and providing the link between the researchers and the playgroup participants. They kept detailed records, provided participant feedback and helped coordinate the process evaluation data collection.

\subsection{Program Participants}

The intervention group consisted of 249 mothers aged 18 and over; with at least one child between 0 to 5 years. The participants needed to be healthy to the extent that participation in a low-stress physical activity program would not place them at risk; not taken part in any research that involved physical activity or nutrition within the previous five years; not on a special diet; and registered with Playgroup WA. Participants were recruited from 30 playgroups based in the Perth metropolitan area with the assistance of Playgroups WA (peak playgroup body in WA).

\subsection{Process Evaluation Methods}

The process evaluation gathered data from two perspectives, those of program staff and those of the participants (mothers of young children). Both qualitative and quantitative data were obtained via semi-structured interviews, paper based and online surveys. Data were collected about the staff; program activities, resources and overall feedback on the program.

\subsection{Program Staff}

\subsubsection{On-Line Survey}

Fourteen program staff completed a 10 minute online survey. The staff were contacted by email and invited to complete the survey via Survey Monkey. Informed consent was obtained via email prior to completion of the survey. The survey aimed to determine barriers and facilitators to using the playgroup setting; requests for health information; reported misconceptions around health; and demographic data of the program staff.

\subsubsection{Interviews}

Twelve program staff completed a semi-structured interview which expanded on the information gathered via the online survey. The interview was designed to assess the factors related to the suitability of the playgroup setting for the delivery of the intervention for the mothers with children between 0 and 5 years; and the suitability of the program content and resources. The interview schedule explored the responses to the online survey. The interviews were conducted by a trained researcher via telephone and were generally of 30 minutes in duration. Prior to commencement of the interview, the aim of the research was explained and informed consent was obtained. Participants received a \$20 gift voucher as an incentive.

\subsection{Participants}

\subsubsection{Self-Complete Surveys}

Surveys were completed by the participants at two time points during the six-month intervention. Survey one ( $\mathrm{n}=194$ : third month) was designed to determine participant perception of staff facilitation and presentation skills at workshops. Survey two $(\mathrm{n}=174$ : sixth month) assessed the usefulness, relevance and suitability of all the intervention strategies and resources for supporting management and changes in physical activity and nutrition behaviours; overall perception of the program; and potential intervention improvements.

The purpose of the surveys was explained to the participants and informed consent was obtained. The surveys were distributed at the playgroups and collected on completion. The questions contained in the surveys used a 5-point Likert scale (ranging from "strongly agree" to "strongly disagree"; "very useful" to "not at all useful"; "very relevant" to "not relevant”) along with several open-ended questions.

\subsubsection{Semi Structured Exit Interviews}

Twenty semi-structured exit interviews (10 completers and 10 non-completers) were conducted with randomly selected program participants, who were invited by telephone to participate in the exit interviews. A trained external researcher conducted the interviews to reduce bias. The interviews were conducted in the participants' homes or at a convenient location and were up to $60 \mathrm{mi}$ nutes in duration. Permission was sought for recording the interviews and a \$20 gift voucher was provided as an incentive. Questions included how effective the program was, usefulness of resources and how the program could be improved. It incorporated both qualitative and quantitative questions.

\subsection{Data Analysis}

Quantitative data was coded and analysed using the Statistical Package for the Social Sciences (SPSS 18.0) computer statistical software. Descriptive statistics were used to summarise participants' demographic and health characteristics. Qualitative data were entered in NVivo, a qualitative data analysis package. The qualitative data were reviewed by two staff members. Content analysis and inductive reasoning were conducted and and salient themes were identified. Ethics approval was obtained 
from the Curtin University Human Research Ethics Committee (approval number HR 183/2008).

\section{RESULTS}

\subsection{Program Staff}

The majority of staff were aged 20 to 24 years (71\%), had a Health Science degree (80\%) and between three to 24 months experience working in the area of health promotion (76\%).

\subsection{Interview and Online Survey}

The program staff reported that the participants were receptive to information and motivated to understand the information provided. Staff reported that the participants requested dietary related information about carbohydrates, proteins, and fats and how they function in the body, how to creatively include vegetables in family meals, tips on healthy eating for the whole family and healthy recipe menu planning. Participants requested information about strategies to resist eating high calorie foods. The physical activity topics about which participants wanted information included how to fit physical activity around family activities, types of exercises that could be completed at home, activities they could complete with their children and realistic expectations of weight loss after pregnancy. Participants also requested information about strategies to maintain weight while attending to the family needs. Interestingly the staff reported a range of misconceptions around nutrition and physical activity (see Table 1).

\subsection{Participants}

The majority of participants were aged 31 to 40 years (75\%), most were in paid employment (60\%), born in Australia (66\%) and had two or more children (67\%). Approximately half (51\%) of the participants had a university degree (see Table 2).

\subsection{Participant's Feedback about Intervention}

\subsubsection{Home-Based Components}

Most participants indicated that the home-based component (comprised of a pedometer, menu planner, shopping list, exercise chart, menu planner and program booklet) were useful, comprehensive, helpful, and valuable if they could not attend the workshops. Participants reported that these resources were as good as attending a workshop, "very helpful as I missed a couple of sessions and handouts and resources were excellent and extremely informative". Participants indicated the healthy eating resources provided interesting food information and were generally a good reminder when planning meals, doing

Table 1. Nutrition and physical activity misconceptions.

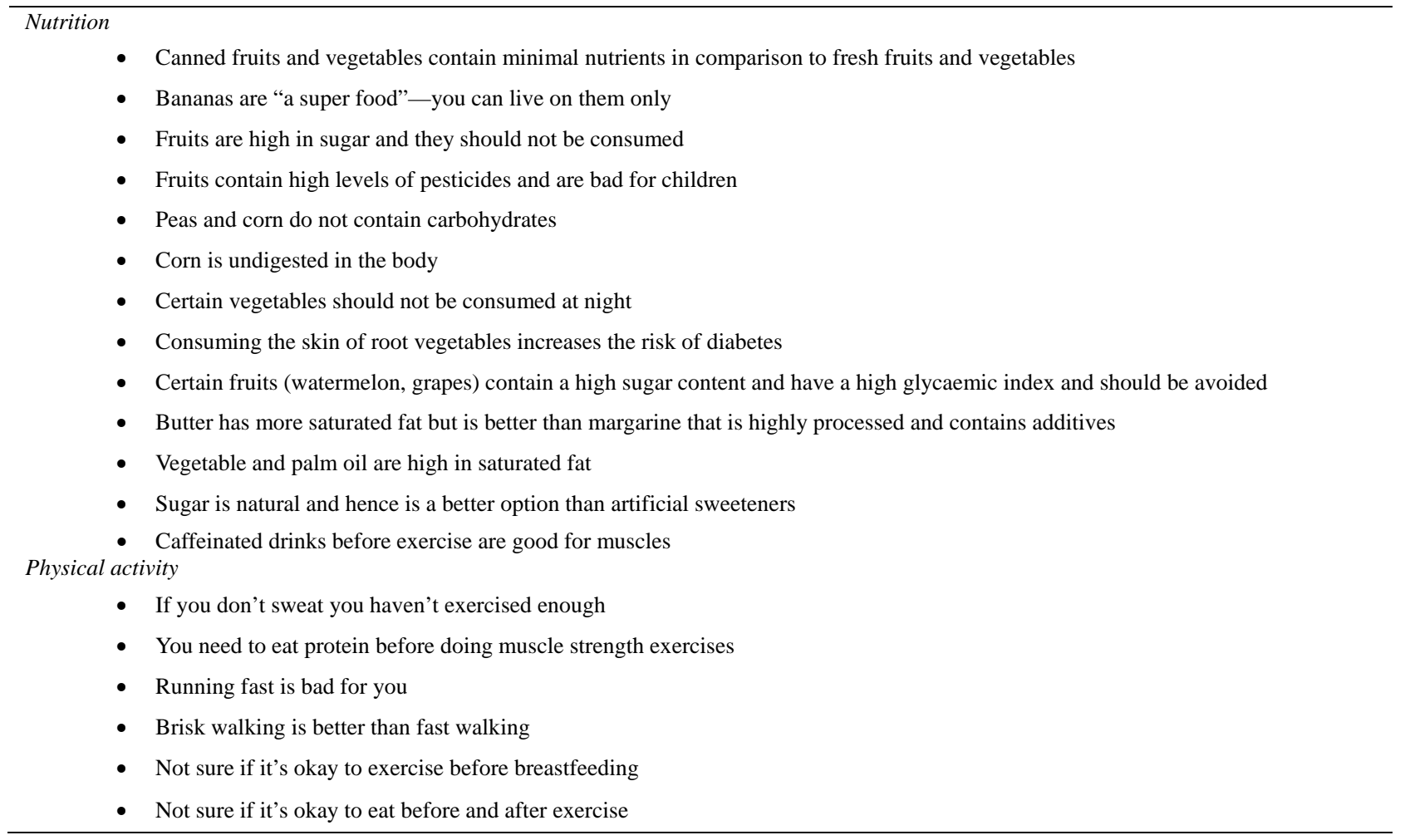


Table 2. Demographics of participants $(n=249)$.

\begin{tabular}{|c|c|}
\hline & N (\%) \\
\hline \multicolumn{2}{|l|}{ Mothers age (years) } \\
\hline 21 to 30 & $23(9.2 \%)$ \\
\hline 31 to 40 & $187(75.1 \%)$ \\
\hline 41 and above & 39 (15.7\%) \\
\hline Pregnant/breastfeeding/postpartum & $103(41.4 \%)$ \\
\hline \multicolumn{2}{|l|}{ Parity (\%) } \\
\hline 1 & $82(32.9 \%)$ \\
\hline 2 & 167 (67.1\%) \\
\hline \multicolumn{2}{|l|}{ Education } \\
\hline Year 12/TAFE & $115(46.2 \%)$ \\
\hline University & 127 (51.0\%) \\
\hline Born in Australia & $165(66.3 \%)$ \\
\hline Married/Partner & 245 (98.8\%) \\
\hline \multicolumn{2}{|l|}{ Employment } \\
\hline Casual & $33(13.3 \%)$ \\
\hline Full/Part-time & $117(47.0 \%)$ \\
\hline \multicolumn{2}{|l|}{ Income } \\
\hline$>\$ 50,999$ & $32(13.4 \%)$ \\
\hline$\$ 51,000$ to $\$ 100,999$ & 95 (39.9\%) \\
\hline$<\$ 101,000$ & 111 (46.0\%) \\
\hline
\end{tabular}

shopping and modifying recipes to be healthier. "There were... facts and things that I didn't know... it made me rethink... just a little bit more awareness of what you're eating and what things contain."

Participants indicated that the booklet encouraged them to think about physical activity and nutrition behaviours (93\%). Other supporting resources such as the pedometer (70\%), menu planner (81\%) and shopping list (88\%) were all reported to be useful and were well received. See Table 3 for a summary of the responses.

\subsubsection{Newsletter}

Participants reported that the newsletters were a useful method of providing nutrition and physical activity information. "They (newsletters) made you understand the correct information about lots of topics (nutrition and physical activity)", "they (newsletters) helped to change my behaviour as I now had information from the dietician rather than a magazine."

\subsection{Short Message Services (SMS)}

Approximately half the participants reported that the
Table 3. Participant responses to statements relating to program resources.

\begin{tabular}{|c|c|c|}
\hline \multicolumn{3}{|l|}{ Agree/Strongly agree with statement } \\
\hline \multicolumn{3}{|l|}{ Booklet $(n=149)$} \\
\hline Useful advice in booklet & $97 \%$ & $(n=144)$ \\
\hline Easy to understand & $95 \%$ & $(n=142)$ \\
\hline Suitability for mothers & $97 \%$ & $(n=145)$ \\
\hline Interesting information in booklet & $98 \%$ & $(n=146)$ \\
\hline Attractive format & $90 \%$ & $(n=134)$ \\
\hline Messages were relevant & $91 \%$ & $(n=136)$ \\
\hline Encouraged me physical activity & $93 \%$ & $(\mathrm{n}=139)$ \\
\hline Encouraged me to think about nutrition & $93 \%$ & $(n=139)$ \\
\hline \multicolumn{3}{|l|}{ Workshop sessions $(\mathrm{n}=170)$} \\
\hline Sessions were useful & $86 \%$ & $(n=146)$ \\
\hline Attendance at sessions & $66 \%$ & $(51 \%-82 \%)$ \\
\hline \multicolumn{3}{|l|}{ MYC resources } \\
\hline Newsletters were useful & $73 \%$ & $(\mathrm{n}=122)$ \\
\hline The pedometer was useful & $70 \%$ & $(n=120)$ \\
\hline The exercise chart was useful & $57 \%$ & $(n=96)$ \\
\hline Shopping List and the Food Label magnet & $88 \%$ & $(n=149)$ \\
\hline Recipe booklet was useful & $81 \%$ & $(\mathrm{n}=136)$ \\
\hline \multicolumn{3}{|l|}{ MYC Activities } \\
\hline The goal setting was useful & $52 \%$ & $(n=106)$ \\
\hline Useful SMS reminder messages & $57 \%$ & $(\mathrm{n}=90)$ \\
\hline The 16 week physical activity diary was useful & $34 \%$ & $(n=56)$ \\
\hline The Walk to the Gold Coast activity was useful & $29 \%$ & $(n=48)$ \\
\hline Flexibility and muscle strength exercise & $39 \%$ & $(\mathrm{n}=48)$ \\
\hline \multicolumn{3}{|l|}{ Program overall } \\
\hline The program was useful & $98 \%$ & $(\mathrm{n}=148)$ \\
\hline The program was relevant to me & $92 \%$ & $(\mathrm{n}=138)$ \\
\hline Encouraged me to think about dietary changes & $98 \%$ & $(n=149)$ \\
\hline Encouraged physical activity changes & $95 \%$ & $(\mathrm{n}=150)$ \\
\hline Helped me change my nutrition behaviours & $79 \%$ & $(\mathrm{n}=132)$ \\
\hline Helped me change physical activity behaviours & $66 \%$ & $(\mathrm{n}=110)$ \\
\hline I would recommend the program to others & $84 \%$ & $(n=144)$ \\
\hline
\end{tabular}

SMS reminders (57\% agreed) were useful. Participants reported that SMS were an effective method to remind them to attend the workshops and bring program resources. "Very good reminders-particularly as we're all 
busy mums". "It helped me to remember and focus on the program" and "It was a good non-intrusive way of communication with the participants". However, some participants did not take notice of the SMS received from the program and some preferred not to receive them. "I use SMS for urgent messages, would have preferred emails" and "I never really read them (SMS)".

\subsection{Workshops}

Of those who responded to the survey one, the majority of participants stated that the purpose of the workshop sessions were clear (99\% agreed: $\mathrm{n}=187$ ); were well organised (98\% agreed: $n=189$ ), and there were sufficient discussion opportunities (97\% agreed: $n=188$ ). Participants described the sessions as inspiring, providing helpful reminders for eating healthily and physical activity, and useful information and resources. Most participants reported that the staff were well informed $(97 \%$ agreed: $n=192)$, easy to understand (99\% agreed: $n=$ 192 ) and kept the focus of the session on the objectives (97\% agreed: $\mathrm{n}=189$ ).

The monthly workshops were not attended by all participants $(n=249)$, with attendance decreasing over the six-month intervention. Attendance at workshop one was $82 \%(\mathrm{n}=202)$; workshop two was $71 \%(\mathrm{n}=175)$; workshop three was $65 \%(\mathrm{n}=161)$; workshop four was $66 \%(\mathrm{n}=164)$; workshop five was $59 \%(\mathrm{n}=147)$ and workshop six was $51 \%(n=127)$.

\subsection{Overall Program Response}

Participants responding to survey two reported that the program had helped them to change their nutrition (79\%: $\mathrm{n}=132)$ and their physical activity behaviours $(66 \%: \mathrm{n}=$ 110). Participants reported that the program made them think more often about what they are eating, plan meals ahead and understand the difference between diet versus healthy eating: "I think that I've gained an appreciation of what kind of information is out there about healthy eating... I did go through and picked out what I thought was the most helpful... from the information we got from I definitely found that it was valuable and worth keeping.

Suggested improvements to the program included provision of child care for workshop walking groups. In regard to resources it was suggested that there be provision of more recipes; sample shopping lists; information via email and online; a workbook; and an interactive website with a discussion board. The main reasons reported for dropping out were returning to work and changes in children's sleep patterns.

\section{DISCUSSION}

\subsection{Overall Triangulation of Data}

The process evaluation results are very positive from both the staff and program participant perspective and compare favourably when compared to other process evaluations conducted by other projects $[28,29]$. The close contact that program staff maintained with the participants, may have assisted in increasing the accuracy and hence the validity of the staffs' perceptions of the program. In turn the data collected from the participants should substantiate that reported by the program staff. This triangulation of data from both the program staff and program participants strengthens the reported results [28].

\subsection{Home-Based Component}

A pilot research project in playgroups conducted by the researchers [30], along with formative data [10] informed the development of the program, indicating that the home based component should be the main focus of the intervention, as all the resources that were provided could be used by the women independently at home at a suitable time. The home-based program especially the flagship booklet were all reported to be useful and were well received by the women. The other supporting resources such as the pedometer, menu planner and shopping list were also rated positively.

\subsection{Workshops}

The workshops were designed to complement and reinforce the home-based resources while providing a means of interacting with and engaging with the participant population. Workshops can be problematic, especially with this target group, as attendance can decline over time due to competing priorities [10]. Attendance of mothers at the workshops did drop off throughout the program with $82 \%$ of mothers attending in the first month, while in the sixth month only $51 \%$ attended. The relatively short timeframe during playgroup meetings, and the need to attend to children are recognised as barriers to regular workshop attendance [10,31,32].

\subsection{Misconceptions}

An interesting and useful component of the study was the women's reported misconceptions. The education level of this study population was a reasonably high ( $51 \%$ university educated), yet there were some curious misconceptions or beliefs. These included, "Peas and corn do not contain carbohydrates", "certain vegetables should not be consumed at night and caffeinated drinks before exercise are good for muscles". This "misconceptions" discussion supported interaction between participants and staff, as staff could respond to these statements and further engage women in the program. The staff were trained in motivational interviewing, a technique that enabled the staff to assist the mothers to ex- 
plore these misconceptions and often assist in resolving them.

Overall the program participants were positive in regard to the program resources and strategies and reported that the program helped them to change their nutrition (79\%) and physical activity (66\%) behaviours, which is an extremely positive reflection. The women also made a number of recommendations for future programs. These included providing sample shopping lists; information via email, a workbook; and an interactive website with a discussion board. All these suggested strategies are suitable for women in paid employment or those working at home caring for their children.

\section{LIMITATIONS}

Between $60 \%$ and $69 \%$ of participants responded to the process evaluation and this may have biased some of the results. However, the response rates compare favourably with similar process evaluations reported in the literature for this population of interest [33]. Also due to the close relationship between staff and participants it is possible there was some social desirability when reporting outcomes. However, all reported data were anonymous and non-identifiable which was likely to minimise potential biases.

\section{CONCLUSION}

The reported outcomes of physical activity and nutrition interventions for mothers with young children have increased gradually over the last two decades but few studies have reported detailed process evaluations of such programs. The process evaluation data indicated that the intervention's unique features such as using multiple strategies and targeting mothers via playgroups ensured that the program reached and engaged a significant proportion of the target group throughout the six month intervention. The mothers were positive about the various strategies and resources used in the intervention, indicating that the program had been implemented and delivered as intended. The combination of the home-based components supported by the interactive workshops was a suitable approach. The suggestions for improvements and refinements of the participants will be useful to make future community based health promotion interventions even more relevant to the priority population. It is recommended that more interventions include detailed process evaluation as part of their research methodology.

\section{ACKNOWLEDGEMENTS}

We would like to thank Playgroups WA for their collaboration with this project; NHMRC for funding; and Sharyn Burns, Carlie Jones, Andrew Hills, Annie Anderson and the women who participated in the study for their valuable contributions.

\section{REFERENCES}

[1] World Health Organisation (2009) Global health risks: Mortality and burden of disease attributable to selected major risks. World Health Organisation, Geneva.

[2] World Health Organisation (2005) Preventing chronic disease a vital investment: WHO Global Report, Geneva.

[3] Davis, E.M., Stange, K.C. and Horwitz, R.I. (2012) Childbearing, stress and obesity disparities in women: A public health perspective. Maternal and Child Health Journal, 16, 109-118.

[4] Thangaratinam, S. and Jolly, K. (2010) Obesity in pregnancy: A review of reviews on the effectiveness of interventions. British Journal of Obstetrics and Gynaecology, 117, 1309-1312. http://dx.doi.org/10.1111/j.1471-0528.2010.02670.x

[5] Tsoi, E., Shaikh, H., Robinson, S. and Teoh, T.G. (2010) Obesity in pregnancy: A major healthcare issue. Postgraduate Medical Journal, 86, 617-623. http://dx.doi.org/10.1136/pgmj.2010.098186

[6] Australian Bureau of Statistics (2009) National health survey: Users' guide-Electronic publication, 2007-08. Canberra.

http://www.abs.gov.au/AUSSTATS/abs@.nsf/DetailsPage /4363.0.55.0012007-08

[7] Brown, W.J., Heesch, K.C. and Miller, Y.D. (2009) Life events and changing physical activity patterns in women at different life stages. Annals Behavioral Medicine, 37, 294-305.

[8] Amorim, A.R., Linne, Y.M. and Lourenco, P.M.C. (2007) Diet, exercise, or both, for weight reduction in women after childbirth. Cochrane Database of Systematic Reviews, 3, Article ID: CD005627.

[9] Kuhlmann, A.K.S., Dietz, P.M., Galavotti, C. and England, L.J. (2008) Weight-management interventions for pregnant or postpartum women. American Journal of Preventive Medicine, 34, 523-528. http://dx.doi.org/10.1016/j.amepre.2008.02.010

[10] Hartman, M.A., Hosper, K. and Stronks, K. (2010) Targeting physical activity and nutrition interventions towards mothers with young children: A review on components that contribute to attendance and effectiveness. Public Health Nutrition, Cambridge, 1-18.

[11] Boutron, I., Moher, D., Altman, D., Schulz, K. and Ravaud, P. (2008) Extending the CONSORT statement to randomized trials of nonpharmacologic treatment: Explanation and elaboration. Annals of Internal Medicine, 148, 295-309. http://dx.doi.org/10.7326/0003-4819-148-4-200802190-0 $\underline{0008}$

[12] Armstrong, R., Waters, E., Moore, L., Riggs, E., Cuervo, L.G., Lumbiganon, P., et al. (2008) Improving the reporting of public health intervention research: Advancing Trend and consort. Journal of Public Health, 30, 103-109. http://dx.doi.org/10.1093/pubmed/fdm082

[13] O’Connor-Fleming, M.L., Parker, E., Higgins, H. and 
Gould, T. (2006) A framework for evaluating health promotion programs. Health Promotion Journal of Australia, 17, 61-66.

[14] Nutbeam, D. and Bauman, A. (2006) Evaluation in a nutshell. MacGraw-Hill, Sydney.

[15] Hubley, J. (2004) Communicating health: An action guide to health education and health promotion. MacMillan, London.

[16] Jancey, J., Clarke, A., Howat, P., Lee, A. and Shilton, T. (2008) A physical activity program to mobilize older people: A practical and sustainable approach. The Gerontologist, 48, 251-257.

[17] Hawe, P., Degeling, D. and Hall, J. (1990) Evaluating health promotion: A health workers guide. MacLennan and Petty, Sydney.

[18] Rootman, I., Goodstadt, M., Potvin, L. and Springett, J. (2001) A framework for health promotion evaluation. WHO Regional Publications European Services, 92, 7-32.

[19] Munro, A., and Bloor, M. (2010) Process evaluation: The new miracle ingredient in public health research? Qualitative Research, 10, 699-713. http://dx.doi.org/10.1177/1468794110380522

[20] Monteiro, S.M., Jancey, J., Howat, P., Burns, S., Jones, C., Dhaliwal, S.S., et al. (2011) The protocol of a randomized controlled trial for playgroup mothers: Reminder on Food, Relaxation, Exercise, and Support for Health (REFRESH) Program. BMC Public Health, 11, 648.

[21] Glanz, K., Rimer, B.K. and Lewis, F.M. (2008) Health behaviour and health education: Theory, research and practice. Jossey-Bass, San Francisco.

[22] Green, L. and Kreuter, M. (2005) Health program planning: An educational and ecological approach. 4th Edition, McGraw Hill, New York.

[23] Bandura, A. (2001) Social cognitive theory: An agentic perspective. Annual Review of Psychology, 52, 1-26. http://dx.doi.org/10.1146/annurev.psych.52.1.1

[24] Resnicow, K., DiIorio, C., Soet, J., Borrelli, B., Ernst, D., Hecht, J., et al. (2002) Motivational interviewing in medical and public health settings. Guilford Press, New York, 251-269.
[25] Department of Health and Ageing (2005) Food for health: Dietary guidelines for Australians, a guide to healthy eating. National Health and Medical Research Council, Canberra.

[26] US Department of Health and Human Services (USDHHS) (2008) Physical Activity Guidelines for Americans.

[27] Egger, G., Donovon, R., Swinburn, B., Giles-Corti, B. and Bull, F.C. (1999) Physical activity guidelines for Australians: Scientific background report. A report by the University of Western Australia and The Centre for Health Promotion and Research Sydney for the Commonwealth Department of Health and Aged Care.

[28] Olvera, N., Knox, B., Scherer, R., Maldonado, G., Sharma, S., Alastuey, L., et al. (2008) A healthy lifestyle program for Latino daughters and mothers: The BOUNCE overview and process evaluation. American Journal of Health Education, 39, 283. http://dx.doi.org/10.1080/19325037.2008.10599052

[29] Burke, L., Jancey, J., Howat, P., Lee, A. and Kerr, D. (2012) Physical activity and nutrition for seniors (PANS): Process evaluation. Health Promotion Practice, 14, 543551 http://dx.doi.org/10.1177/1524839912461504

[30] Jones, C., Jancey, J, Howat, P., Burns, S. and McManus, A. (2010) Report of the mothers with young children physical activity and nutrition playgroup intervention. Healthway Report, Perth.

[31] Marcus, B.H. and Forsyth, L.H. (1998) Tailoring interventions to promote physically active lifestyles in women. Women's Health Issues: Official publication of the Jacobs Institute of Women's Health, 8, 104-111.

[32] Jones, C., Burns, S., Howat, P., Jancey, J., McManus, A. and Carter, O. (2010) Playgroup as a setting for nutrition and physical activity interventions for moths with young children: Exploratory qualitative findings. Health Promotion Journal of Australia, 21, 92-98.

[33] Walker, R., Turnbull, D., Pratt, N. and Wilkinson, C. (2005) The development and process evaluation of an information-based intervention for pregnant women aimed at addressing rates of caesarean section. British Journal of Obstetrics and Gynaecology, 112, 1605-1614. 